\title{
Prophylactic Extraction of Third Molars: Justified or Not?
}

\author{
T Srinivasa Prasad
}

\begin{abstract}
Aim: Removal of the third molars is the most common minor oral surgical procedure being performed. Though controversy is minimal when there is a pathology involved with the third molar, prophylactic removal of impacted third molars has always been debated. This review focuses on the prophylactic removal of the third molar
\end{abstract}

Background: Many a time an impacted third molar can remain asymptomatic throughout life. What is to be considered is the risk of just retaining an asymptomatic third molar against overt problems that arise if it becomes pathological.

Review results: Quite a number of systematic reviews have been compiled by various authors on this topic. However, still, there is no decision with a black and white certainty when it comes to prophylactic removal of impacted third molars.

Conclusion: This article highlights the review on surgical removal of impacted molars, the associated complications during removal and the complications associated with retention.

Keywords: Impacted, Prophylactic removal, Third molar.

How to cite this article: Prasad TS. Prophylactic Extraction of Third Molars: Justified or Not?. World J Dent 2019;10(1):72-77.

Source of support: Nil

Conflict of interest: None

\section{INTRODUCTION}

Third molars are the terminal teeth in terms of both position and eruption chronology. The normal eruption period for wisdom teeth falls between the ages of 17-26 years. ${ }^{1}$ More often these teeth fail to erupt or only partially erupt and hence over the time have earned the position of vestigial organs. ${ }^{2}$ Impacted third molars are commonly encountered conditions in the oral cavity. When a tooth fails to erupt into its anatomical position within its developmental window, it is considered impacted. The oral cavity can function optimally devoid of third molars, and hence the significance of these teeth has diminished over time. ${ }^{2}$ Removal of impacted third molars irrespective of their pathologic status has been in practice for about 25 years now. ${ }^{3}$ However the associated

Meenakshi Ammal Dental College and Hospital, Chennai, Tamil Nadu, India

Corresponding Author: T Srinivasa Prasad, Meenakshi Ammal Dental College and Hospital, Chennai, Tamil Nadu, India, e-mail: drgpsujatha@gmail.com complications and increased financial expenses have raised the question whether the prophylactic extractions of third molars are justified or not.

On the contrary, concern regarding retaining the asymptomatic impacted third molar still exists as it can increase the risk of pathology to surrounding tissues in due course of time. Further complications are far more if the tooth is removed at an older age when it becomes symptomatic. ${ }^{4}$ Hence a long-standing debate prevails on whether to retain or remove asymptomatic and impacted third molars. This review article aims to provide insights on surgical removal of impacted molars, the associated complications during removal and the complications associated with retention.

\section{Defining an Impacted Tooth}

Impaction is defined as the cessation of the eruption of the tooth caused by a clinically and radiographically detectable physical barrier in the eruption path or by an ectopic position of tooth. ${ }^{5}$ Third molars are the most commonly impacted tooth. ${ }^{6}$ The attributes to the commonness of occurrence of this event are given by phylogenic, Mendelian, and orthodontic theories. ${ }^{7}$ In this review, the term impacted the third molar includes unerupted, impacted and partially impacted teeth. An impacted tooth can be covered by only soft tissue or partly or completely by bone.

\section{Defining an Asymptomatic Tooth}

There is little or no controversy when an impacted third molar in a disease state is removed. This can include unrestorable caries, recurrent periodontitis, cysts, etc. The term 'asymptomatic' simply means symptom-free and not disease free. The tooth is considered asymptomatic when the patient experiences no pain or discomfort associated with it. Understanding the semantic uncertainty around the term 'asymptomatic' is important. A tooth can be asymptomatic when it is actually not disease free. Impacted wisdom teeth can be painless but might have signs of pathosis clinically or radiographically. Therefore the term 'asymptomatic' does not guarantee a 'risk-free' state. ${ }^{8,9}$

\section{Defining Prophylactic Removal}

The principle of prevention is rarely applied to surgical interventions with one such paradoxical combination 
being surgical removal of asymptomatic impacted teeth. ${ }^{10}$ Prophylactic removal in this article refers to the extraction of asymptomatic pathology-free impacted third molars as a preventive measure. Impaction of wisdom teeth can be considered developmental abnormality which predisposes to conditions like periodontitis, caries, cysts or tumors that can advance asymptomatically. ${ }^{11}$ Moreover, the predictability of the asymptomatic impacted tooth becoming pathological in the future is enigmatic. Hence the practice of prophylactic removal of the third molars was thought to be justified.

\section{Pathologies Associated with Impacted Third Molars}

Impacted third molars can by themselves be affected by periodontitis, caries or be associated with cysts and tumors. ${ }^{12}$ The impacted molar can destroy an adjacent tooth by causing resorption or dental caries. The occurrence of dental caries in the second molars due to the third molar is about $4.5 \% .^{13,14}$ Root resorption of 2 nd molars due to the impacted tooth accounts to only $1 \%$ of the cases. ${ }^{15,16}$ Pericoronitis is often seen in association with an impacted third molar. This occurs commonly in young adults where the surrounding gingival tissue gets inflamed. ${ }^{13}$ Cysts can also arise although the incidence is very low. Malignancies can develop from the dental follicle of the impacted tooth. ${ }^{13}$ However, the chance of a tumor occurring is extremely low. Although it appears that the likely occurrence of some serious pathology is low, it is to be stressed that they cannot be overlooked:

- Cysts: Dentigerous cysts are commonly occurring among developmental cysts and are convincingly more associated with third molars than the other teeth. This cyst often prevents the eruption of third molars making them impacted. ${ }^{17}$ Several studies have reported the incidence of dentigerous cyst which ranges between $1-2 \%{ }^{18-20}$ The occurrence of cystic changes in the follicle has been correlated to the age of the patient in one study which showed that the patients falling in the age groups of 20-25 years are more prone. Hence, they concluded age could be an indicator for prophylactic extraction further substantiating with the fact that the risk of surgical morbidity increases with age. ${ }^{21,22}$

- Tumors: The probability of occurrence of ameloblastoma, epidermoid carcinoma, odontogenic carcinoma, etc. have been insisted as a strong indication for prophylactic extraction of third molars. ${ }^{21,23,24}$ Guven et al. ${ }^{25}$ has reported the incidence of ameloblastoma in an impacted third molar to be $0.41 \%$ while Shear and $\operatorname{Singh}^{26}$ reported it to be $2 \%$. The incidence of malignancies around the impacted tooth is found to be less than $1 \% .^{25}$ Eversole et al. ${ }^{24}$ in his article spell out that about half of the mucoepidermoid carcinomas are associated with impacted teeth.

- Pericoronitis: Recurrent pericoronitis are a well-known indication to the extraction of third molars. However, in certain cases a simple excision of the operculum might prove to be useful. ${ }^{27}$ Hence it is important to assess the predictability concerning the eruption of third molars using proper radiographic aids.

- Fractures: Evidence sheds light on the association of mandibular impacted third molars with the mandibular angle and condylar fractures. Zhu et al. ${ }^{28}$ in his retrospective study state that the frequency of mandibular angle fractures is higher in patients with unerupted third molar than others. He also concludes that the frequency of condylar fractures is less in patients with impacted third molars. The reason given for increased risk of an ankle fracture is that the impacted tooth occupies the majority of the osseous portion in the angle area. Reitzik et al. ${ }^{29}$ in an animal study deciphered that it took only $60 \%$ of the optimal force required to fracture the angle in a mandible with an impacted third molar.

\section{Reasons for Prophylactic Extraction}

The concept of preventive extraction comes into play when the retention of an asymptomatic impacted third molar is considered a threat or a risk factor due to one of the following reasons: ${ }^{4}$

- To reduce the occurrence of future diseases in the third molar

- Orthodontic reasons to prevent crowding in the future

- Performing surgery at an older age will increase the risk of complications

- When there are specific medical or surgical conditions.

However, the importance given to asymptomatic impacted third molars as risk factors could be little belabored. ${ }^{30,31}$ Many times, an impacted third molar can remain asymptomatic throughout life. ${ }^{32}$ What is to be considered is the risk of just retaining an asymptomatic third molar against overt problems that arise if it becomes pathological. Also, the risk of retaining the tooth should be weighed against the complications or morbidity associated following removal.

\section{UNDERSTANDING 'TRADE-OFF'}

Two schools of thought exist when it comes to removal of third molars. When the tooth is associated with pathology, it is an absolute indication for extraction. However, if the impacted tooth is asymptomatic the following are to be considered. ${ }^{4}$ 
- The morbidity associated with retention until pathology emerges and complications of curative removal

- The benefits and complications associated with prophylactic removal.

Thus the pans of the balance contain morbidity associated with retaining the tooth on one side with the morbidity associated with removing on the other. ${ }^{8}$

\section{RETENTION VERSUS REMOVAL OF ASYMPTOMATIC IMPACTED THIRD MOLARS}

There are potentially numerous complications that can occur due to prophylactic surgical removal of impacted third molars. ${ }^{14}$ The pros and cons of removing the tooth are discussed below.

\section{Complications Following Surgery}

Common complications following surgery include the followings-dry socket, infection, hemorrhage and pain. ${ }^{12}$ Fracture of the tuberosity or lingual plate can occur during the surgery. ${ }^{9}$ Delayed or defective healing, disto-molar pockets can occur postoperatively.9,33 The maxillary tooth during surgery can slip into the maxillary sinus, pterygopalatine space or infratemporal space. ${ }^{9,33,34}$ Temporomandibular disorders can arise due to excessive and strained mouth opening during the procedure. ${ }^{35,36}$ Dysesthesia can occur due to iatrogenic damage of the inferior alveolar nerve. 9,35,36 Sensory nerve damage during the procedure has been observed to occur at a rate of $0.5-20 \% .^{13,14,37}$ About $35 \%$ of the complications that occur are dry socket. ${ }^{14}$

\section{Outcomes Associated with Retaining the Third Molar}

A prospective cohort study by Nunn et al. ${ }^{38}$ showed that there is no significant difference between the presence or absence of impacted third molar in terms of distal second molar probing depth $>4 \mathrm{~mm}$. The risk of alveolar bone loss in the second molar was less in the absence of impacted third molar than when it was present. Nunn et al. $^{38}$ further concluded that the occurrence of caries in second molars does not differ significantly in either of the cases. Dimensional changes in the dental arch as influenced by the presence or absence of impacted third molars were assessed in a randomized control trial by Harradine et al., ${ }^{39}$ and the results were inconclusive.

\section{PEEK INTO THE LITERATURE-ADDRESSING THE LACUNAE}

Quite a number of systematic reviews have been compiled by various authors on this topic. ${ }^{4,8,12,40-42}$ However, still, there is no decision with a black-and-white certainty when it comes to prophylactic removal of impacted third molars. The quality of evidence that has been gleaned so far is suggested to be low. There is an explicit scarcity of papers with good scientific merit to assess the primary and secondary outcomes of retaining or removing impacted third molars. In fact, no studies address the primary outcome, i.e., the health-related quality of liferelated to the removal/retention of asymptomatic impacted third molars. There is a lack of credible and valid scientific documentation to support or reject the prophylactic removal of asymptomatic impacted third molars. ${ }^{4,40,41}$

However, on analyzing the available evidence, the proponents of the motion justify the prophylactic extraction of asymptomatic impacted third molars for various reasons. Apart from pathology, asymptomatic tooth removal is justified if there are any underlying medical condition or for orthodontic and prosthodontic reasons. ${ }^{1,43}$ These, however, are not based on sound scientific research. Wang et al. ${ }^{44}$ and Yamanik et al. ${ }^{45}$ support prophylactic intervention as they suggest partially erupted the third molar is more commonly found to develop pericoronitis. The prophylactic extraction of asymptomatic impacted third molar is warranted in order to prevent distocervical caries in 2nd molars according to McArdle and Renton. ${ }^{46}$ Kan et al. ${ }^{47}$ bases the concept of prophylactic extraction of asymptomatic impacted third molars due to its ill effects on the periodontium.

Although the good quality of evidence on this notion is sparse, clinical practical guidelines (CPG) are available for about 20 years now. The Scottish Intercollegiate guideline network (1999) and the National Institute for health and care excellence (2000) published a set of CPG on the management of impacted wisdom teeth. Both the reports counsel against the prophylactic extraction of asymptomatic impacted third molars in light of the costs and morbidity associated with its removal. ${ }^{40}$ McArdle and Ranton ${ }^{46}$ in their review article point out that the introduction of CPG has not led to the decline of impaction procedures but rather has increased the number of wisdom teeth requiring removal at an older age owing to caries. Richardson and Dodson $^{48}$ do not favor the notion as the risk of distomolar pockets arising is more following the removal of third molars. A "wait and see conduct" approach is suggested by Song et al. ${ }^{12}$ Another concern in retaining asymptomatic third molars is the late incisor crowding that is feared to occur. Studies done by Lindqvist and Thilander ${ }^{16}$ could not predict the influence of third molars over the change in dental arch dimensions.

\section{Indian Population Studies}

The incidence of pathology associated with asymptomatic impacted third molars in the Indian population has been 
documented by Patil et al. ${ }^{49}$ and Vigneswaran et al. ${ }^{50}$ Both studies agree that the incidence of cysts or tumors in the third molars is very low. Patil et al. ${ }^{49}$ reported that a considerable number of patients had disease-free third molars. However a minority yet a significant number of the patients were identified with pathology. He, therefore, suggested regular and constant monitoring of the asymptomatic impacted third molars in all patients to promptly intervene if any pathology arises. Vigneswaran and Shilpa ${ }^{50}$ in their six-year-long epidemiological study identified 70 cases with pathology amongst a sample of 2778 patients with asymptomatic impacted third molars. They advocated that clinical and radiographical assessments alone are not enough to detect pathologies. Histopathological examination of the tissues is imperative for a definitive diagnosis. The authors believe the policy of prevention and hence endorse prophylactic removal of impacted third molars irrespective of the symptom status. There is a scarcity of literature on the practice types or decision-making ideas of Indian dentists when it comes to asymptomatic impacted third molar management. Data on the knowledge attitude and practices of dentists in India on the prophylactic extraction of third molars are essential to formulate policies and bring about rationale clinical practice.

\section{ARRIVING AT A CONSENSUS}

The dearth of strong scientific evidence is a disgrace rather than a snag to the era of evidence-based dentistry. Available information from the literature tells us that the dependence of the decision-making process is on the financial constraints and professional liability. Patients' preferences should be valued and given importance when it comes to the removal of disease-free asymptomatic impacted third molars. ${ }^{40}$ Keeping the cost burden and the associated potential complications of third molar removal in mind it is advisable to adopt selective extraction of impacted third molars with pathology particularly in a developing nation like India. In such cases regular monitoring of asymptomatic impacted third molars become mandatory. The decision to go for prophylactic extractions should not be generalized. It is advisable to limit extraction of impacted third molars with clear pathologic indications. $^{51}$

\section{NEED AND SCOPE FOR RESEARCH}

It is difficult to compare the retention of impacted asymptomatic third molars against their removal partly because the outcomes assessed are different. ${ }^{12}$ However, well designed prospective studies with long term follow up comparing removal and retention of asymptomatic disease-free impacted wisdom teeth are required. Ran- domized control trials comparing prophylactic removal with deliberate retention will provide better evidence than observational studies. ${ }^{40}$ Decision analysis models comparing long term outcomes of retention and removal of asymptomatic impacted third molars are also needed. ${ }^{4,12}$ The health-related quality of life can also be assessed to comprehensively understand the impact of asymptomatic wisdom teeth on the quality of life of an individual. ${ }^{40}$

\section{CONCLUSION}

A lot of discussion in literature has been done to arrive at a consensus. However, the lack of proper scientific evidence proves to be the greatest drawback. With available literature on the prophylactic extraction of third molars, it can be concluded that the preventive approach might not be the best treatment modality when it comes to asymptomatic impacted wisdom teeth. Constant monitoring at regular intervals and patient-centered decision making can help clinicians to devise the optimal treatment until sound evidence through research is produced.

\section{REFERENCES}

1. Kruger E, Thomson WM, Konthasinghe P. Third molar outcomes from age 18 to 26: findings from a population based New Zealand longitudinal study. Oral Surgery, Oral Medicine, Oral Pathology, Oral Radiology, and Endodontics 2001; 92(2):150-155.

2. Bergman J. Are wisdom teeth (third molars) vestiges of human evolution? Journal of Creation. 1998; 12(3):297-304.

3. Brokaw WC. The third molar question: when and why should we recommend removal? Virginia Dental Journal 1991; 68(4):18-21.

4. Stordeur S, Eyssen M. Prophylactic removal of pathologyfree wisdom teeth: rapid assessment. Good Clinical Practice (GCP). Brussels: Belgian Health Care Knowledge Centre (KCE). 2012. KCE Report 182C. D/2012/10.273/49.

5. Purkait SK. Developmental anomalies of oral and para-oral structures. $3^{\text {rd }}$ Ed. Essentials of oral pathology. New Delhi, Jaypee Brothers medical publishers. 2011; p. 39.

6. Peterson LJ. Principles of Management of Impacted Teeth. In: Peterson, Ellis, Hupp, Tucker, editors; Contemporary Oral and Maxillofacial Surgery Missouri: Mosby: 2003. pp. 184-213.

7. Syed KB, Kota Z, Ibrahim M, Bagi MA, Assiri MA. "Prevalence of Impacted Molar Teeth among Saudi Population in Asir Region, Saudi Arabia - A Retrospective Study of 3 Years". J Int Oral Health 2013;5(1):43-47.

8. Godfrey K, Dent KK. Prophylactic removal of asymptomatic third molars: a review. Australian dental journal. 1999; 44(4): 233-237.

9. Alling CC, Alling RD. Indications for management of impacted teeth. In: Alling CC, Helfrick JF, Alling RD, eds. Impacted teeth. Philadelphia: WB Saunders; 1993.

10. Friedman JW. Containing the cost of third-molar extractions: a dilemma for health insurance. Public Health Reports. 1983; 98(4):376.

11. Faculty of Dental Surgery of the Royal College of Surgeons of England. Report of a working party convened by the 
Faculty of Dental Surgery. Current clinical practice and parameters of care. The management of patients with third molar (syn: wisdom) teeth. London: Faculty of Dental Surgery RCS (Eng), 1997. http://www.rcseng.ac.uk/fds/ publications-clinical guidelines/clinical_guidelines/ documents/3rdmolar.pdf.

12. Song F, O'meara S, Wilson P, Golder S, Kleijnen J. The effectiveness and cost-effectiveness of prophylactic removal of wisdom teeth. Health Technology Assessment (Winchester, England). 2000;4(15):1-55.

13. Daley TD. Third molar prophylactic extraction: a review and analysis of the literature. Gen Dent 1996; 44: 310-320.

14. Mercier P, Precious D. Risks and benefits of removal of impacted third molars. A critical review of the literature. J Oral Maxillofac Surg 1992;21:17-27.

15. Von-Wowern N, Nielsen HO. The fate of impacted lower third molars after the age of 20. Int J Oral Maxillofac Surg 1989;18: 277-280.

16. Lindqvist B, Thilander B. Extraction of third molars in cases of anticipated crowding in the lower jaw. Am J Orthod 1982; 81:130-139.

17. Shafer WG, Hine MK, Levy BM. A Textbook of Oral Pathology. 4th ed., Philadelphia, W.B. Saunders Company, 1983, p. 260.

18. Mourshed F. A roentgenographic study of dentigerous cyst. Oral Surg 1964;18:47-53.

19. Keith DA. The detection of abnormalities in the jaws-a survey. Br Dent J 1973;134:129-135.

20. Alattar MM, Baughman RA, Collett WK. A survey of panoramic radiographs for evaluation of normal and pathologic findings. Oral Surg 1980;50:472-478.

21. Rakprasitkul S. Pathologic changes in the pericoronal tissues of unerupted third molars. Quintessence Int 2001;32: 633-638.

22. Baykul T, Saglam AA, Aydin U, Basak K. Incidence of cystic changes in radiologically normal impacted lower third molar follicles. Oral Surg Oral Med Oral Pathol Oral Radiol Endod 2005;99:542-545.

23. Yasuoka T, Yonemoto K, Kato Y, Tatematsu N. Squamous cell carcinoma arising in a dentigerous cyst. J Oral Maxillofac Surg 2000;58:900-905.

24. Eversole LR, Sabes WR, Rovin S. Aggressive growth and neoplastic potential of odontogenic cysts. Cancer 1975;35: 270-282.

25. Guven 0, Keskin A, Akal UK. The incidence of cysts and tumors around impacted third molars. Int J Oral Maxillofac Surg 2000;29:131-135.

26. Shear M, Shigh S. Age-standardized incidence rates of ameloblastoma and dentigerous cyst on the Witwatersrand, South Africa. Comm Dent Oral Epidemiol 1978; 6: 195-199.

27. National Institute of Health Consensus Development Conference Summaries, Vol. 2. Removal of Third Molars. NIDR, 1979.

28. Zhu S-J, Choi B-H, Kim H-J, Park W-S, Huh J-il., Jung J-H, Kim B-Y, Lee S-H. Relationship between the presence of unerupted mandibular third molars and fractures of the mandibular condyle. Int J Oral Maxillofac Surg 2005;34:382-385.

29. Reitzik M, Lownie JF, Cleaton-Jones JP, Austin J. Experimental fractures of monkeys mandibles. Int J Oral Surg 1978;7: 100-103.

30. Shepherd J, Brickley M. Surgical removal of third molars. Prophylactic surgery should be abandoned. BMJ 1994; 309: 620-621.
31. Stephens R, Kogon S, Reid J. The unerupted or impacted third molar - a critical appraisal of its pathologic potential. J Can Dent Assoc 1989;55:201-207.

32. Ahlqwist M, Grondahl HG. Prevalence of impacted teeth and associated pathology in middle-aged and older Swedish women. Community Dent Oral Epidemiol 1991;19:116-119.

33. Laskin DM. Oral and maxillofacial surgery. St Louis: CV Mosby, 1985;2:30-60.

34. Kaban LB, Pogrel MA, Perrott DH. Complications in oral and maxillofacial surgery. Philadelphia : WB Saunders, 1997: 60-66.

35. Ricketts RM. The dilemma of the third molar. In: Schatz JP, Joho JP, eds. Minor surgery in orthodontics. Chicago: Quintessence Publishing; 1992.

36. Chiapasco M, De Cicco L, Marrone G. Side effects and complications associated with third molar surgery. Oral Surg Oral Med Oral Pathol 1993;76:412-420.

37. Carmichael FA, McGowan DA. Incidence of nerve damage following third molar removal: a west of Scotland Oral Surgery Research Group Study. Br J Oral Maxillofac Surg 1992;30:78-82.

38. Nunn ME, Fish MD, Garcia RI, Kaye EK, Figuerosa R, Gohel A, et al. Retained asymptomatic third molars and risk for second molar pathology. Journal of Dental Research 2013; 92(12):1095-1099.

39. Harradine NW, Pearson MH, Toth B. The effect of extraction of third molars on late lower incisor crowding: a randomized controlled trial. British Journal of Orthodontics 1998; 25(2):117-122.

40. Ghaeminia H, Perry J, Nienhuijs ME, Toedtling V, Tummers M, Hoppenreijs TJ, Van der Sanden WJ, Mettes TG. Surgical removal versus retention for the management of asymptomatic disease-free impacted wisdom teeth. The Cochrane Library; 2016.

41. Costa MG, Pazzini CA, Pantuzo MC, Jorge ML, Marques LS. Is there justification for prophylactic extraction of third molars? A systematic review. Brazilian Oral Research. 2013;27 (2): 183-188.

42. Mettes TD, Ghaeminia H, Nienhuijs ME, Perry J, Van der Sanden WJ, Plasschaert A. Surgical removal versus retention for the management of asymptomatic impacted wisdom teeth. Cochrane Database Syst Rev. 2012;6.

43. Chaparro-Avendaño AV, Pérez-García S, Valmaseda-Castellón E, Berini-Aytés L, Gay-Escoda C. Morbidity of third molar extraction in patients between 12 and 18 years of age. Med Oral Patol Oral Cir Bucal. 2005;10(5):422-431.

44. Wang XL. Correlation study on acute pericoronitis and the position of the mandibular impacted third molar. Shanghai Kou Qiang Yi Xue. 1995;4(2):70-72. Chinese.

45. Yamalik K, Bozkaya S. The predictivity of mandibular third molar position as a risk indicator for pericoronitis. Clin Oral Investig. 2008;12(1):9-14.

46. McArdle LW, Renton TF. Distal cervical caries in the mandibular second molar: an indication for the prophylactic removal of the third molar? Br J Oral Maxillofac Surg. 2006; $44(1): 42-45$.

47. Kan KW, Liu JK, Lo EC, Corbet EF, Leung WK. Residual periodontal defects distal to the mandibular second molar 6 - 36 months after impacted third molar extraction. J Clin Periodontol. 2002;29(11):1004-1011.

48. Richardson DT, Dodson TB. Risk of periodontal defects after third molar surgery: An exercise in evidence-based clinical 
decision-making. Oral Surg Oral Med Oral Pathol Oral Radiol Endod. 2005;100(2):133-137.

49. Patil S, Halgatti V, Khandelwal S, Santosh BS, Maheshwari S. Prevalence of cysts and tumors around the retained and unerupted third molars in the Indian population. Journal of oral biology and craniofacial research. 2014;4(2):82-87.
50. Vigneswaran AT, Shilpa S. The incidence of cysts and tumors associated with impacted third molars. Journal of pharmacy \& bioallied sciences. 2015;7(Suppl 1):S251.

51. Adeyemo WL, Ladeinde AL, Olugbemiga MM. Prophylactic surgical removal of impacted third molars: Contemporary views. Pakistan Oral Dent J. 2005;25:11-14. 